\title{
DESAIN MODEL PEMBELAJARAN BLENDED LEARNING PADA PERKULIAHAN HUBUNGAN INTERNASIONAL
}

\author{
Irwan $^{1}$, Monica Tiara ${ }^{2}$, dan Rita Angraini ${ }^{3}$ \\ 1,2,3 Jurusan Ilmu Sosial Politik Universitas Negeri Padang \\ Email: irwanhamdi@fis.unp.ac.id
}

\begin{tabular}{l}
\hline Info Artikel \\
\hline \\
Sejarah Artikel: \\
Diserahkan 7 Agustus 2019 \\
Direvisi 30 September 2019 \\
Disetujui 18 November 2019 \\
\hline \\
Keywords: \\
blended learning, course of \\
international relations, online \\
learning \\
\hline
\end{tabular}

\begin{abstract}
Purpose of this researsch is to describe the design of the blended learning learning model in the course of International Relations in the Department of Social and Political Sciences, Universitas Negeri Padang. Blended Learning is a learning model that combines face-toface lectures in class with online learning based on technology tools.

This research is a qualitative research with descriptive analysis. Data is obtained through literature studies, documentation and asking for the opinions of experts related to the learning model that is appropriately implemented in learning in higher education.

The results of this study are in the form of a learning model design with a combination of face-to-face learning with the use of technology in accordance with teaching materials and learning outcomes in the course of International Relations. Thus the pattern of interaction between lecturers and students is not always in the classroom but on various occasions who remain connected using internet technology tools. The blended learning design developed is expected to be coherent with the achievement of International Relations learning that has been compiled while increasing the mastery of technology by students and lecturers.
\end{abstract}

\begin{abstract}
Abstrak
Tujuan penelitian ini yaitu untuk mendeskripsikan desain model pembelajaran blended learning pada perkuliahan Hubungan Internasional di Jurusan Ilmu Sosial Politik Universitas Negeri Padang. Blended Learning merupakan model pembelajaran yang menggabungkan perkuliahan tatap muka di kelas dengan perkuliahan daring yang berbasis pada teknologi.

Penelitian ini merupakan penelitian kualitatif dengan analisis deskriptif. Data didapatkan melalui studi literatur, dokumentasi serta meminta pendapat para ahli terkait dengan model pembelajaran yang tepat diimplementasikan dalam pembelajaran di perguruan tinggi.

Hasil penelitian ini berupa desain model pembelajaran dengan kombinasi perkuliahan tatap muka dengan pemanfaatan teknologi sesuai dengan materi-materi ajar dan capaian pembelajaran pada perkuliahan Hubungan Internasional. Dengan demikian pola interaksi antara dosen dan mahasiswa tidak selalu di dalam kelas namun di berbagai kesempatan yang tetap terhubung menggunakan piranti teknologi internet. Desain blended learning yang dikembangkan diharapkan koheren dengan capaian pembelajaran HI yang telah disusun sekaligus meningkatkan penguasaan teknologi oleh mahasiswa dan dosen.
\end{abstract}

(C) 2019 Universitas Muria Kudus 
Irwan, Monica Tiara, dan Rita Angraini

DESAIN MODEL PEMBELAJARAN BLENDED LEARNING PADA PERKULIAHAN ...

REFLEKSI EDUKATIKA : Jurnal Ilmiah Kependidikan 10 (1) Desember 2019. Hlm. 48-57

\section{PENDAHULUAN}

Era Revolusi Industri 4.0 yang terus bergulir di seluruh dunia telah membuka mata masyarakat akan pentingnya penguasaan teknologi di setiap lini kehidupan. Teknologi seolah menjadi urat nadi bagi masyarakat karena memberi peran yang besar dalam kemajuan di segala bidang. Tidak terkecuali di Indonesia, pemanfaatan teknologi telah menjadi kebutuhan pokok bagi generasi penerus, mulai dari kalangan anak-anak hingga dewasa. Hal ini disebabkan salah satunya karena teknologi dapat memberi kemudahan, efisiensi dan efektivitas pada suatu pekerjaan.

Sektor pendidikan sebagai salah satu sektor yang vital dalam penyelenggaraan negara mestinya dapat memanfaatkan kemajuan teknologi sebagai basis untuk menciptakan kemajuan dan peningkatan kualitas pendidikan. Irwan, dkk (2019) menyatakan bahwa perkembangan teknologi dapat menjadi penentu kemajuan di dunia pendidikan saat ini. Penentu disini maksudnya adalah teknologi menjadi instrumen dalam mewujudkan pendidikan yang bagus dan berkualitas. Senada dengan pendapat (Muhson, 2010) yang menyatakan bahwa pendidikan memiliki peran yang besar bagi pengembangan ilmu pengetahuan dan teknologi tersebut. Namun di sisi lain pendidikan juga perlu memanfaatkan kemajuan ilmu pengetahuan dan teknologi demi mampu mencapai tujuannya secara efektif dan efisien.

Tantangan di abad 21 saat ini adalah mengintegrasikan teknologi pada dunia pendidikan. Sebab kedua variabel ini tidak bisa lagi dipisahkan. Mewujudkan pendidikan yang berkualitas bukanlah tanggung jawab pendidik saja namun juga dari peserta didik. Amin (2017) mengatakan bahwa perlu ada kerjasama yang kohesif antara pendidik dengan peserta didik agar proses pembelajaran memberikan hasil yang optimal. Sebuah laporan dengan judul "Learning for the $21^{\text {st }}$ Century" mempublikasikan "Framework for $21^{\text {st }}$ Century Learning” (Marzano \& Heflebower, 2011) dimana telah dijelaskan setidaknya terdapat empat kompotensi atau bidang yang harus dikuasai oleh pendidik dan peserta didik yang meliputi "1) core subject and $21^{\text {st }}$ century themes, 2) learning and innovative skills, 3) information media and technology skills and 4) life and career skills". Poin pertama meliputi kompetensi pedagogi keilmuan yakni kemampuan seorang pendidik terhadap suatu bidang ilmu. Kompetensi tersebut harus in-line dengan kebutuhan abad 21. Setelah memiliki kompetensi dalam bidang keilmuwan, aspek selanjutnya yaitu seorang pendidik harus memiliki kemampuan dalam mengajar dan berinovasi dalam pembelajaran. Seorang pendidik tentu tidak cukup menguasai kompetensi pedagogy saja karena kapasitasnya bukan sebagai pakar namun yang terpenting adalah bagaimana kemampuan berinovasi dan melaksanakan proses pembelajaran yang tepat sehingga peserta didik dapat memahami dan mengerti dengan bidang ilmu yang diajarkan. Kemudian kompetensi dalam menguasai teknologi informasi dan media menjadi sesuatu yang mutlak di tengan perkembangan teknologi saat ini. Poin ketiga ini sejalan dengan desain pembelajaran yang seyogyanya berbasis pada teknologi. Ketiga kompetensi tersebut jika dapat dilakukan dengan baik maka akan menunjang karir pendidik untuk masa mendatang.

Seiring dengan perkembangan Ilmu Pengetahuan dan Teknologi saat ini, maka implementasi media pembelajaran berbasis pada teknologi sudah menjadi sebuah kebutuhan. Sadiman dalam (Rahmatullah, 2011) menyatakan media pembelajaran sebagai sarana dalam menyalurkan pesan pembelajaran. Sebagai sarana dalam menyalurkan pesan, maka media memegang peranan penting dalam proses pembelajaran. Jika dosen hanya berkutat pada metode pengajaran tatap muka, berbagai permasalahan yang disebutkan di atas tidak akan melahirkan solusi yang optimal. Penerapan unsur teknologi dalam dunia pendidikan dikenal dengan istilah e-learning atau pembelajaran secara online. Menurut Sari (2013), pembelajaran online yaitu pelaksanaan proses belajar mengajar yang menggunakan perangkat teknologi berupa internet sebagai pengganti dari pembelajaran tatap muka di kelas. Dengan menggunakan teknologi internet maka dosen dan mahasiswa dapat melaksanakan proses belajar mengajar dimanapun mereka berada. Sofiana (2015) menyatakan bahwa jika perkuliahan e-learning dilaksanakan dengan baik, maka dapat menghemat waktu, baik waktu bagi dosen maupun mahasiswa. Negara-negara maju sudah terlebih dahulu menggunakan metode ini sebagai dampak dari meluasnya penggunaan piranti teknologi di bidang pendidikan. Sebagai negara berkembang dan salah satu konsumen teknologi terbesar di dunia, tentu peluang penetrasi teknologi dalam ranah pendidikan menjadi penting dan dirasa sudah tepat. Bahkan model e-learning telah diterima secara luas di seluruh dunia sejak 1970 (Sriwardiningsih, 2014). 
Irwan, Monica Tiara, dan Rita Angraini

DESAIN MODEL PEMBELAJARAN BLENDED LEARNING PADA PERKULIAHAN ...

REFLEKSI EDUKATIKA : Jurnal Ilmiah Kependidikan 10 (1) Desember 2019. Hlm. 48-57

Akan tetapi kenyataanya tidak semua pendidik bersedia untuk sepenuhnya beralih menggunakan sistem kuliah online yang selanjutnya disebut daring. Hal itu disebabkan terdapat beberapa materi ajar yang lebih tepat disampaikan dengan metode tatap muka. Demi menyiasati soalan tersebut, pilihan yang rasional yaitu menggunakan kedua metode dalam satu semester ajar. Penggunaan kedua metode pembelajaran ini dikenal dengan nama metode blended learning. Secara harfiah blended diartikan 'campuran', dengan demikian blended learning merupakan proses pembelajaran yang menggabungkan metode tatap muka (face to face) dengan metode daring. Dengan demikian dalam satu semester perkuliahan, dosen dapat mengombinasikan kedua metode pembelajaran sesuai dengan kebutuhan saat itu. Kerres dan Witt dalam Fariska (2017) menyatakan bahwa kombinasi antara pembelajaran berbasih online dan pembelajaran tatap muka dapat menjadi sebuah strategi pembelajaran. Sebab kedua model ini memiliki kelebihan dan kekurangan masing-masing yang dapat disiasati dengan metode campuran /blended learning. Namun Kuntarto (2016) dalam penelitannya lebih menekankan pada aspek positif penggunaan media online dengan alasan bahwa pembelajaran akan lebih efektif, beroritentasi tujuan, mampu mengubah rutinitas perkuliahan serta evaluasi ssecara lebih luas.

Metode blended learning ini dapat digunakan oleh dosen-dosen dalam bidang kajian apapun salah satunya pada Jurusan Ilmu Sosial Politik misalnya mata kuliah Hubungan Internasional. Hubungan Internasional untuk selanjutnya disebut HI merupakan salah satu kajian keilmuan yang berada pada rumpun ilmu sosial. (McClelland dan Adil, 1986) mendefinisikan HI sebagai studi tentang interaksi antar jenis kesatuan-kesatuan tertentu, termasuk studi tentang kondisi-kondisi yang relevan. Fenomena HI terjadi paling sedikit oleh dua aktor. Aktor dalam HI yaitu pihak yang melakukan interaksi dengan pihak lain dengan syarat melewati batas-batas teritorial negara tersebut. Interaksi yang terjadi tidak hanya dengan motif politik namun menyangkut segala aspek misalnya pendidikan, kunjungan wisata, bekerja yang melibatkan dua negara atau lebih. Kompleksitas hubungan antar aktor dapat dijelaskan pada gambar berikut ini: 


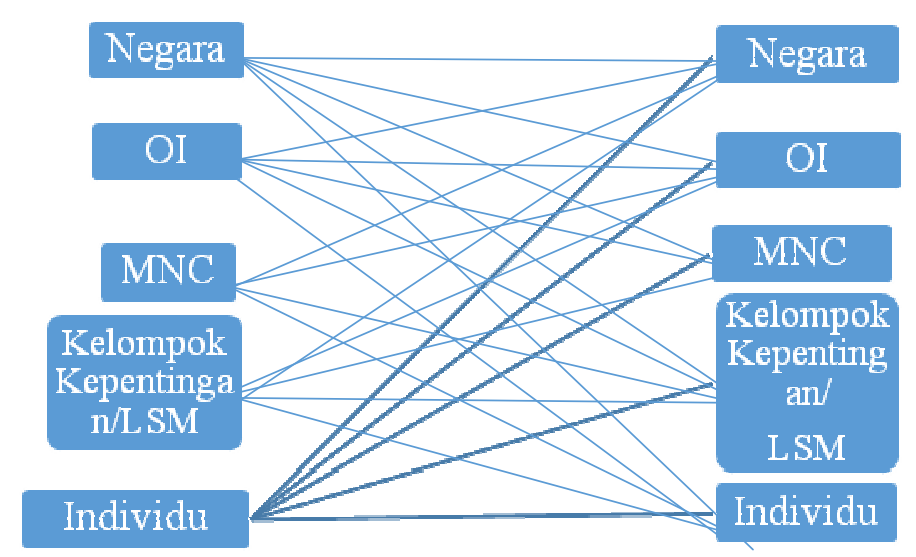

Gambar 1. Kompleksitas Hubungan Internasional (olahan sendiri)

Gambar di atas menunjukkan sejumlah aktor yang berperan dalam hubungan internasional. Mulai dari skala kecil yaitu individu, kemudian kelompok kepentingan atau lembaga swadaya masyarakat, perusahaan multi nasional, organisasi internasional dan terakhir negara sebagai aktor utama dalam HI. Setiap aktor saling berinteraksi dan berhubungan dengan aktor lain dalam bidang-bidang apapun menyangkut kepentingan nasional aktor tersebut.

Perwita \& Yani (2005) menyatakan bahwa HI merupakan suatu kajian tentang politik luar negeri dan politik internasional yang berhubungan dengan seluruh negara di dunia dalam berbagai bentuk. Dengan demikian studi hubungan internasional berarti suatu kajian tentang kebijakan dan politik luar negeri suatu negara sebagai aktor HI dalam hubungan dan interaksinya dengan aktor lain yang melintasi batas-batas antar negara dalam upaya mencapai suatu tujuan tertentu.

Mayoritas perguruan tinggi baik di dalam maupun luar negeri menjadikan kajian HI sebagai salah satu program studi yang mandiri dan berada di bawah Fakultas Ilmu Sosial dan Ilmu Politik. Di sisi lain HI juga digabung pada kajian ilmu politik atau ilmu sosial. Berbeda dengan kampus pendidikan seperti Universitas Negeri Padang dimana tidak memiliki jurusan atau Prodi HI sehingga kajian HI hanya menjadi salah satu mata kuliah wajib bagi mahasiswa di Jurusan Ilmu Sosial Politik. Studi HI digabungkan dengan studi Kewarganegaraan, Politik, Hukum dan rumpun ilmu sosial lainnya yang dikenal dengan kajian multidisiplin. Kajian yang multidisiplin menyebabkan tidak semua mahasiswa jurusan Ilmu Sosial Politik menyukai mata kuliah Hubungan Internasional.
Ketidaktertarikan mahasiswa terhadap mata kuliah HI tentu patut menjadi perhatian para pendidik.

Anggraeni (2012) mengindentifikasi beberapa persoalan yang terjadi pada perkuliahan $\mathrm{HI}$ diantaranya, pertama $\mathrm{HI}$ dianggap sebagai mata kuliah yang membosankan karena berisi cukup banyak teori yang harus dihafalkan. Kedua, meskipun memahami konsep dasar, para mahasiswa tidak memahami makna dan intisari kajian HI. Ketiga, berkaitan dengan ketidakmampuan mahasiswa dalam memecahkan masalah global menggunakan konsep-konsep yang telah dipelajari. Keempat, kurangnya inisiatif untuk mengemukakan pendapat dan mengelola suatu perdebatan di dalam kelas. Kelima, dosen hanya berorientasi pada capaian target yaitu penguasaan materi oleh mahasiswa sehingga cenderung mengabaikan prosesnya. Padahal sejatinya mempelajari HI berarti mencoba mengamati, menganalisis dan mengkritisi fenomena dan gejolak yang terjadi di dunia baik di masa lampau maupun kontemporer.

Hasil penelitian Sriwardiningsih menunjukkan bahwa perilaku belajar mahasiswa pada model e-learning sangat berkaitan dengan variabel kurikulum, interaksi dosen, mahasiswa, admin, sampai ke motivasi (Sriwardiningsih, 2014). Dengan demikian keterhubungan antar aspek menjadi penting agar tidak menimbulkan permasalahan di atas.

Berbagai persoalan di atas jika diabaikan maka justru akan menurunkan kualitas dan kompetensi mahasiswa terhadap mata kuliah HI. Selain itu juga akan menurunkan kualitas dosen sebagai pendidik karena tidak mampu dalam men-deliver ilmu pengetahuan terhadap mahasiswa. Oleh karena itu penerapan metode 
Irwan, Monica Tiara, dan Rita Angraini

DESAIN MODEL PEMBELAJARAN BLENDED LEARNING PADA PERKULIAHAN ..

REFLEKSI EDUKATIKA : Jurnal Ilmiah Kependidikan 10 (1) Desember 2019. Hlm. 48-57

blended learning dalam perkuliahan HI menjadi satu alternatif solusi yang dapat diterapkan oleh dosen di kelas dalam menyelesaikan lima kendala pembelajaran $\mathrm{HI}$ di atas. Selain itu metode ini diharapkan efektif dalam mencapai target capaian pembelajaran sesuai RPS. Berikut materi-materi utama dalam perkuliahan $\mathrm{HI}$ beserta capaian pembelajarannya selama satu semester perkuliahan.

Tabel.1 Capaian Pembelajaran HI (Tim Penyusun RPS Hubungan Internasional, 2019)

\begin{tabular}{|c|c|c|}
\hline $\begin{array}{l}\text { Daftar } \\
\text { Pertemuan }\end{array}$ & Materi Pokok & Capaian Pembelajaran \\
\hline 1 & $\begin{array}{l}\text { Definisi dan ruang } \\
\text { lingkup HI }\end{array}$ & $\begin{array}{l}\text { Mahasiswa mampu menjelaskan definisi } \\
\begin{array}{l}\text { lingkup hubungan internasional } \\
\text { ingerta }\end{array} \\
\text { internasional sebagai disiplin ilmu. }\end{array}$ \\
\hline II \& III & Subyek dan Objek HI & $\begin{array}{l}\text { Mahasiswa mampu mengidentifikasi subjek dan objek } \\
\text { hubungan internasional, kemudian mampu } \\
\text { mendeskripsikan objek kajian hubungan internasional. }\end{array}$ \\
\hline IV & $\begin{array}{l}\text { Sistem dalam Hubungan } \\
\text { Internasional }\end{array}$ & $\begin{array}{l}\text { Mahasiswa mampu mendeskripsikan sistem hubungan } \\
\text { internasional sebelum abad ke-21 dan sistem hubungan } \\
\text { internasional kontemporer }\end{array}$ \\
\hline $\mathrm{V} \& \mathrm{VI}$ & $\begin{array}{l}\text { Politik luar negeri dan } \\
\text { kepentingan nasional }\end{array}$ & $\begin{array}{l}\text { Mahasiswa mampu dalam mengidentifikasi pola politik } \\
\text { luar negeri Indonesia dalam berinteraksi dengan negara } \\
\text { lain. Kemudian juga dapat menjelaskan kaitan politik luar } \\
\text { negeri dengan kepentingan nasional. }\end{array}$ \\
\hline VII \&VIII & $\begin{array}{l}\text { Kekuatan nasional dalam } \\
\text { hubungan internasional }\end{array}$ & $\begin{array}{l}\text { Mahasiswa mampu mengidentifikasi modal-modal dasar } \\
\text { nasional dalam hubungan internasional dan dilanjutkan } \\
\text { dengan melakukan analisis posisi suatu negara dalam } \\
\text { hubungan internasional. }\end{array}$ \\
\hline $\bar{X}$ & $\begin{array}{l}\text { Instrumen dan teknik } \\
\text { hubungan internasional }\end{array}$ & $\begin{array}{l}\text { Mahasiswa mampu menganalisis tentang instrumen dan } \\
\text { teknik hubungan internasional. }\end{array}$ \\
\hline XI \& XII & Dasar-dasar keimigrasian & $\begin{array}{l}\text { Mahasiswa mampu menguasai pengetahuan, sikap, } \\
\text { keterampilan tentang keimigrasian. }\end{array}$ \\
\hline XIII & $\begin{array}{l}\text { Hubungan diplomatik } \\
\text { dan konsuler }\end{array}$ & $\begin{array}{l}\text { Mahasiswa mampu menguasai pengetahuan, sikap, dan } \\
\text { keterampilan tentang hubungan diplomatik dan konsuler. }\end{array}$ \\
\hline XIV \& XV & Organisasi internasional & $\begin{array}{l}\text { Mahasiswa dapat menguasai struktur, peran dan } \\
\text { pentingnya kerjasama melalui organisasi internasional. }\end{array}$ \\
\hline XVI & $\begin{array}{l}\text { Hubungan internasional } \\
\text { pasca perang dingin dan } \\
\text { setelah } 11 \text { September } \\
2001\end{array}$ & $\begin{array}{l}\text { Mahasiswa mampu menganalisis kecendrungan hubungan } \\
\text { internasional abad ke- } 21 \text {. }\end{array}$ \\
\hline
\end{tabular}

Tabel diatas memberi gambaran urgensi capaian pembelajaran dalam setiap materi pembelajaran. Pasalnya, pencapaian keberhasilan capaian pembelajaran merupakan tolak ukur keberhasilan proses pembelajaran. Oleh karena itu, artikel ini bertujuan untuk mendeskripsikan desain model pembelajaran blended learning pada perkuliahan Hubungan Internasional di Jurusan Ilmu Sosial Politik Universitas Negeri Padang. Lebih lanjut, artikel ini menemukan desain model blanded learning untuk mengoptimalkan proses pembelajaran yang efektif dan efisien.

\section{METODE PENELITIAN}

Penelitian ini merupakan jenis penelitian kualitatif dengan teknik analisis deskriptif. Metode deskriptif merupakan metode dalam meneliti status sekelompok manusia, suatu objek, suatu set kondisi, suatu sistem pemikiran, atau pun suatu kelas peristiwa pada masa sekarang (Moleong, 2004). Peneliti menciptakan sebuah desain pembelajaran pada mata kuliah Hubungan Internasional dengan menggabungkan perkuliahan tatap muka dengan perkuliahan daring dengan jumlah yang proporsional sesuai dengan capaian pembelajaran pada tiap-tiap materi. Penelitian 
Irwan, Monica Tiara, dan Rita Angraini

DESAIN MODEL PEMBELAJARAN BLENDED LEARNING PADA PERKULIAHAN ..

REFLEKSI EDUKATIKA : Jurnal Ilmiah Kependidikan 10 (1) Desember 2019. Hlm. 48-57

dilakukan terhadap mahasiswa yang mengambil mata kuliah Hubungan Internasional di jurusan Ilmu Sosial Politik Universitas Negeri Padang. Data didapatkan melalui studi literatur, dokumentasi serta pendapat-pendapat para pakar pendidikan yang relevan dengan topik yang diteliti yakni para dosen bidang ilmu kependidikan dan ilmu Hubungan Internasional.

\section{HASIL DAN PEMBAHASAN}

Mata kuliah Hubungan Internasional merupakan mata kuliah wajib di jurusan Ilmu Sosial Politik dengan Karakteristik penguasaan pemahaman dan pengetahuan, sikap, keterampilan dalam hal Hubungan Internasional. Dengan karakteristik yang ada, mata kuliah HI bersifat lebih dinamis dengan materi yang cenderung aktual. Sehingga proses pembelajaran $\mathrm{HI}$ perlu untuk terus dilakukan pembaharuan dalam rangka peningkatan kualitas pendidikan khususnya pembelajaran. Hal ini dikarenakan Pembelajaran merupakan kegiatan yang esensial dalam pendidikan. Proses pembelajaran pada hakikatnya menjadi proses komunikasi yang di dalamnya terdapat berbagai kegiatan, salah satu diantaranya adalah penyampaian materi pelajaran.

Hasil temuan menunjukkan bahwa Desain Model Pembelajaran Blended Learning Pada Perkuliahan Hubungan Internasional berdampak pada proses pembelajaran yang lebih praktis dan efisien. Pembelajaran berlangsung tidak lagi sekedar mengejar target untuk menghindari sanksi akademik, tetapi menjadi proses pembelajaran yang bermakna dalam mewujudkan setiap capaian pembelajaran. Bahkan hasil penelitian Rovai dan Jordan dalam Sofiana (2015) menunjukkan bahwa pembelajaran dengan model blended learning lebih memberikan rasa kebersamaan satu sama lain daripada dengan metode tatap muka biasa. Kesimpulan lain dari Sulistiyoningsih (2015) juga mengungkap bahwa blended learning pada dasarnya tidak mengurasi interaksi dosen dan dan guru namun sebaliknya akan meningkatkan interaksi kedua belah pihak karena adanya keterlibatan lansung mahasiswa dalam pembelajaran, fleksibilitas dan kemajuan secara kontinu. Sebab dengan model ini memberikan kebebasan bagi setiap mahasiswa untuk mengemukakan pendapat tanpa ada pengawasan atau kritikan dari temans atu kelas (Novitayati, 2013). Dengan demikian maka desain Model Pembelajaran Blended Learning Pada Perkuliahan Hubungan Internasional dapat dilaksanakan dengan menyesuaikan karakteristik materi perkuliahan pada setiap pertemuan untuk menjaga frekuensi interaksi mahasiswa dan dosen.

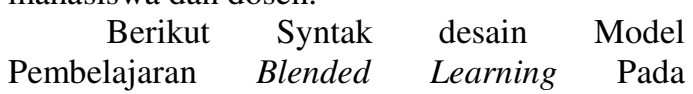
Perkuliahan Hubungan Internasional yang di kembangkan:

a. Perkuliahan Tatap Muka (face to face)

Perkuliahan tatap muka merupakan bagian yang terpenting dan tidak dapat dilepaskan dari setiap proses pembelajaran. Ini merupakan metode klasik dimana adanya komunikasi dan interaksi lansung antara pendidik dan peserta didik secara rutin dan berkesinambungan dalam menyampaikan materi ajar untuk mencapai capaian pembelajaran. Amin (2017) mengatakan bahwa pembelajaran tatap muka sudah ada dan berkembang di dunia sebelum ditemukan perangkagt teknologi seperti komputer, audio, visual, dan lain lain. Perkuliahan tatap muka perlu untuk memberikan pemahaman terhadap peserta didik tentang posisi HI sebagai disiplin ilmu. Sebab, bagi sebagai orang HI tidak lepas dari sekedar kajian tentang hubungan dan konflik antar negara, padahal pada dasarnya terdapat banyak teori-teori tentang perkembangan pemikiran $\mathrm{HI}$ di seluruh dunia dan fenomena yang melingkupinya. Perkuliahan tatap muka dapat dilaksanakan pada beberapa pertemuan awal, tengah semester dan pertemuan akhir semester.

b. Resume berita aktual luar negeri

Berita aktual internasional dapat digunakan sebagai sumber referensi pengetahuan bagi pembelajaran $\mathrm{HI}$ karena pemberitaan media massa sarat isu-isu kontemporer dari berbagai belahan dunia. Terdapat banyak kanalkanal berita yang menyediakan informasi dari dunia internasional. Sumber berita dan informasi dapat berasal dari media cetak berupa koran atau majalah serta media elektronik. Kanal berita tersebut memuat isu-isu yang cukup mendominasi gejolak global seperti hubungan Amerika Serikat dengan China, gejolak perang di Timur Tengah, Imigran Eropa, Proliferasi Nuklir, dan kasus-kasus lainnya. Mahasiswa dapat diberi 
Irwan, Monica Tiara, dan Rita Angraini

DESAIN MODEL PEMBELAJARAN BLENDED LEARNING PADA PERKULIAHAN ..

REFLEKSI EDUKATIKA : Jurnal Ilmiah Kependidikan 10 (1) Desember 2019. Hlm. 48-57

penugasan untuk membaca atau menonton, memahami dan mengkritisi substansi informasi yang disampaikan berdasarkan teori-teori HI yang sudah dipelajari sebelumnya.

c. Studi kasus individu dan kelompok Metode pembelajaran studi kasus yaitu dengan cara meminta mahasiswa untuk mencari, memahami dan menganalisis suatu kasus yang terjadi di suatu negara menggunakan teori-teori HI. Kasus yang terjadi tidak terbatas pada aspek tertentu sepanjang menyangkut hubungan antara dua negara atau lebih. Mahasiswa dapat diberi peran sebagai mediator atau problem solver yang dimiinta untuk menyelesaikan dan mencari solusi dari permasalahan yang dikupas. Metode ini akan meningkatkan pemahaman siswa terhadap suatu teori dan melatih pemecahan masalah-masalah global.

d. Media Youtube

Youtube merupakan salah satu platform daring yang sangat digemari sejak awal mula meningkatnya penggunaan internet hingga saat sekarang. mengatakan bahwa Youtube merupakan sebuah situs yang digunakan sebagai wadah berbagi video antar penggunanya. Media ini sangat efektif dan digandrungi oleh kalangan muda karena dapat memuat konten video apapun misalnya musik, tutorial, film, berita, dan lain-lain. Media youtube dapat menjadi sarana belajar bagi mahasiswa yang dapat diakses dimanapun berada sepanjang ada jaringan internet dan media pemutarnya berupa telepon genggam atau personal komputer. Kuntarto (2016) juga menekankan bahwa media internet seperti youtube ini dapat dipilih sebagai platform dasar dalam menyampaikan materi karena pertimbangan keterjangkauan, efektifitas serta realibilitas program. Dosen dapat memberikan link url kepada mahasiswa agar nanti dilihat atau mahasiswa diminta mencari link sendiri yang berkaitan dengan topik belajar saat itu. Media youtube sudah sering digunakan sebagai media pembelajaran di Indonesia karena menurut Luhsasi dan Sadjiarto (2017) media youtube dapat memberikan informasi yang sangat luas tidak terbatas pada bidang tertentu.. Oleh karena itu youtube juga sangat tepat menjadi alternatif perkuliahan HI.

e. Review film box office

Hubungan internasional merupakan studi tentang hubungan antar negara yang bermuara pada kerjasama atau konflik hingga perang dan damai. Memahami HI dapat pula dilakukan lewat film-film box-office yang memang menjadi bagian dari gaya hidup pemuda sekarang ini. Terdapat banyak film karya hollywood dan rumah produksi lain yang menceritakan tentang konflik dan kerjasama antar negara sehingga in-line dengan studi HI. Meskipun film merupakan cerita fiksi, namun mahasiswa dapat mengambil pelajaran penting dari fenomena yang dicaritakan. Bahkan beberapa diantaranya diangkat dan terinspirasi dari kisah nyata. Mahasiswa dapat diberi penugasan untuk menonton film kemudian membuat review atau refleksi dari film tersebut untuk kemudian menjadi bahan diskusi kelas. Beberapa contoh film yang dapat dijadikan sumber pembelajaran diantaranya The Interpreter (2015), American Sniper (2014), The Interview (2014), Bridge of Spies, dan lain sebagainya.

\section{Berdasarkan syntak tersebut, berikut Desain Blended Learning pada Setiap Materi Ajar HI} sebagaimana tabel di bawah ini:

Tabel 2. Desain Blended Learning pada Setiap Materi Ajar HI

\begin{tabular}{|l|l|l|}
\hline $\begin{array}{l}\text { Daftar } \\
\text { Pertemuan }\end{array}$ & Materi Pokok & Desain Blended Learning \\
\hline 1 & Definisi dan Ruang Lingkup HI & $\begin{array}{l}\text { Metode tatap muka } \\
\text { Untuk memberikan introduction dan posisi kajian HI, }\end{array}$ \\
\hline
\end{tabular}


Irwan, Monica Tiara, dan Rita Angraini

DESAIN MODEL PEMBELAJARAN BLENDED LEARNING PADA PERKULIAHAN ...

REFLEKSI EDUKATIKA : Jurnal Ilmiah Kependidikan 10 (1) Desember 2019. Hlm. 48-57

\begin{tabular}{|c|c|c|}
\hline & & $\begin{array}{l}\text { maka dapat dilaksanakan dengan metode tatap muka } \\
\text { (face to face). }\end{array}$ \\
\hline II \& III & Subyek dan Objek HI & $\begin{array}{l}\text { Metode tatap muka } \\
\text { Subyek dan Obyek merupakan konsep dasar dalam } \\
\text { pembelajaran HI yang lebih baik dilakukan melalui } \\
\text { perkuliahan tatap muka }\end{array}$ \\
\hline IV & $\begin{array}{ll}\text { Sistem dalam } & \text { Hubungan } \\
\text { Internasional } & \end{array}$ & $\begin{array}{l}\text { Resume Berita luar negeri } \\
\text { Agar mahasiswa mampu mendeskripsikan sistem } \\
\text { hubungan internasional sebelum abad ke- } 21 \text { dan } \\
\text { sistem hubungan internasional kontemporer maka } \\
\text { mereka patut meresume berita tentang isu-isu luar } \\
\text { negeri }\end{array}$ \\
\hline $\mathrm{V} \& \mathrm{VI}$ & $\begin{array}{l}\text { Politik Luar Negeri dan } \\
\text { Kepentingan Nasional }\end{array}$ & $\begin{array}{l}\text { Review Film Box Office } \\
\text { Agar mahasiswa mampu mengidentifikasi pola politik } \\
\text { luar negeri Indonesia dalam berinteraksi dengan } \\
\text { negara lain maka pembelajaran melalui media film } \\
\text { adalah salah satu alternatif. }\end{array}$ \\
\hline VII \&VIII & $\begin{array}{lr}\text { Kekuatan Nasional } & \text { dalam } \\
\text { Hubungan Internasional } & \end{array}$ & $\begin{array}{l}\text { Review Film Box Office } \\
\text { Agar mahasiswa mampu mengidentifikasi modal- } \\
\text { modal dasar nasional berupa kekuatan nasional dalam } \\
\text { berinteraksi dengan negara maka perkuliahan dapat } \\
\text { diganti dengan penugasan film box office karena } \\
\text { terdapat banyak film terkait dengan kekuatan nasional } \\
\text { suatu negara. }\end{array}$ \\
\hline $\bar{X}$ & $\begin{array}{l}\text { Instrumen dan Teknik Hubungan } \\
\text { Internasional }\end{array}$ & $\begin{array}{l}\text { Media Youtube } \\
\text { Agar mahasiswa mampu menganalisis tentang } \\
\text { instrumen dan teknik hubungan internasional maka } \\
\text { dapat diberi penugasan mencari video pembelajaran } \\
\text { terkait melalui media youtube }\end{array}$ \\
\hline XI \& XII & Dasar-dasar Keimigrasian & $\begin{array}{l}\text { Tatap Muka dan Penugasan lapangan } \\
\text { Agar mahasiswa mampu menguasai pengetahuan, } \\
\text { sikap, keterampilan tentang keimigrasian maka dapat } \\
\text { dilakukan dengan perkuliahan tatap muka serta } \\
\text { penugasan di lapangan berupa visitasi ke kantor } \\
\text { imigrasi atau dinas terkait. }\end{array}$ \\
\hline XIII & $\begin{array}{l}\text { Hubungan Diplomatik } \\
\text { Konsuler }\end{array}$ & $\begin{array}{l}\text { Studi Kasus Individu dan kelompok } \\
\text { Agar mahasiswa mampu menguasai pengetahuan, } \\
\text { sikap, dan keterampilan tentang hubungan diplomatik } \\
\text { dan konsuler maka dapat dilakukan dengan analisis } \\
\text { kasus baik individu maupun secara kelompok }\end{array}$ \\
\hline XIV \& XV & Organisasi Internasional & $\begin{array}{l}\text { Media Youtube } \\
\text { Agar mahasiswa dapat menguasai struktur, peran dan } \\
\text { pentingnya kerjasama melalui organisasi internasional } \\
\text { maka mahasiswa dapat diberi penugasan melalui } \\
\text { media youtube karena terdapat banyak video } \\
\text { pembelajaran mengenai organisasi internasional. }\end{array}$ \\
\hline XVI & $\begin{array}{l}\text { Hubungan Internasional Pasca } \\
\text { Perang Dingin dan Setelah } 11 \\
\text { September 2001 }\end{array}$ & $\begin{array}{l}\text { Metode Tatap Muka dan Review Film box office } \\
\text { Agar mahasiswa mampu menganalisis kecendrungan } \\
\text { hubungan internasional abad ke- } 21 \text { maka dapat } \\
\text { dilakukan dengan perkuliahan tatap muka dan } \\
\text { dilanjutkan dengan review film box office. Film-film } \\
\text { box office sarat akan fenomena dan gambaran masa } \\
\text { depan (futuristik) sehingga dapat menjadi acuan } \\
\text { perkembangan HI pada abad } 21 \text { dan seterusnya. }\end{array}$ \\
\hline
\end{tabular}


Irwan, Monica Tiara, dan Rita Angraini

DESAIN MODEL PEMBELAJARAN BLENDED LEARNING PADA PERKULIAHAN ...

REFLEKSI EDUKATIKA : Jurnal Ilmiah Kependidikan 10 (1) Desember 2019. H1m. 48-57

\begin{abstract}
Desain Model Pembelajaran Blended Learning Pada Perkuliahan Hubungan Internasional diatas mengacu pada hasil penelitian (Graham, 2005), yakni: (1) seeking of information, (2) acquisition of information, dan (3) synthesizing of knowledge. Tahapan seeking of information, mencakup pencarian informasi dari berbagai sumber informasi yang tersedia, memilih secara kritis diantara sumber penyedia informasi dengan berpatokan pada content of relevantion, content of validity/releability, dan academic clarity. Pada desain ini, dosen berperan sebagai fasilitator dan pakar yang dapat memberikan masukan dan arahan dalam menfokuskan informasi denga materi bahasan. Sementara, pada tahapan acquisition of information, mahasiswa yang telah diarahkan sesuai desain model berupaya untuk menemukan, memahami, serta mengkonfrontasikannya dengan ide atau gagasan yang telah ada dalam pikiran mereka, kemudian menginterprestasikan informasi/pengetahuan dari berbagai sumber yang tersedia, sampai mereka mampu kembali mengkomunikasikan dan menginterpretasikan ide-ide dan hasil interprestasinya.
\end{abstract}

\section{SIMPULAN}

Desain Model Pembelajaran Blended Learning pada perkuliahan Hubungan Internasional dirancang untuk memenuhi kebutuhan dosen dan mahasiswa agar cara belajar mahasiswa bervariasi, menanggulangi kekurangan waktu untuk menyampaikan materi ajar serta membantu mahasiswa memahami materi ajar dengan memanfaatkan fasilitas yang tersedia. Berdasarkan desain model dikembangkan untuk mewujudkan pembelajaran yang praktis dan efisien. Maka desain model dikembangkan dalam syntak berikut: Perkuliahan Tatap Muka (face to face), Resume berita aktual luar negeri, Studi kasus individu dan kelompok, Media Youtube, review film box office. Lebih lanjut, syntak desain model yang juga dapat digunakan pada setiap materi bahasan dalam penerapannya memepertimbangkan beberapa hal, yakni; tujuan pembelajaran yang akan di capai, aktifitas pembelajaran yang relevan serta memilih dan menentukan aktifitas mana yang relevan dengan desain model

\section{DAFTAR PUSTAKA}

Amin, A. K. 2017. Kajian Konseptual Model Pembelajaran Blended Learning berbasis Web untuk Meningkatkan Hasil Belajar dan Motivasi Belajar. Jurnal Pendidikan

\section{Edutama, 4 (2): 51-64.}

Ananda, A., Indrawadi, J., Azmi, A., dan Hamdi, I. 2018. Tim Penyusun RPS Hubungan Internasional. Padang: Jurusan Ilmu Sosial Politik.

Anggraeni, L. 2012. Penerapan Metode Studi Kasus Dalam Upaya Meningkatkan Kemampuan Berpikir Kritis Mahasiswa Pada Mata Kuliah Hubungan Internasional. Media Komunikasi FIS, 11(3).

FARISKA, R. 2017. Blended Learning Untuk Meningkatkan Level Kemampuan Berpikir Kritis. Pendidikan Sains, 5(2).

Graham, C. R. 2005. Blended learning system. Definisi, Current, and Future Directions. Dalam The Hand Book of Blended Learning.

Irwan, I., Luthfi, Z. F., dan Waldi, A. 2019. Efektifitas Penggunaan Kahoot! untuk Meningkatkan Hasil Belajar Siswa [Effectiveness of Using Kahoot! to Improve Student Learning Outcomes]. PEDAGOGIA: Jurnal Pendidikan, 8(1): 95-104.

Kuntarto, E., dan Asyhar, R. 2016. Pengembangan Model Pembelajaran Blended Learning Pada Aspek Learning Design Dengan Platform Media Sosial Online Sebagai Pendukung Perkuliahan Mahasiswa. Repository Unja.

Luhsasi, D. I., dan Sadjiarto, A. 2017. Youtube: trobosan media pembelajaran ekonomi bagi mahasiswa. In Prosiding Seminar Pendidikan Ekonomi dan Bisnis.

Marzano, R. J., dan Heflebower, T. 2011. Teaching \& assessing 21st century skills. Solution Tree Press.

McClelland, C. A., dan Adil, H. 1986. Ilmu Hubungan Internasional: Teori dan Sistem. Rajawali Press.

Moleong, L. J. 2004. Metodologi Penelitian Kualitatif. Bandung: PT Remaja Rosdakarya.

Muhson, A. 2010. Pengembangan media 
pembelajaran berbasis teknologi informasi. Jurnal Pendidikan Akuntansi Indonesia, 8(2).

Novitayati, R. (2013). Pengaruh Metode Blended Learning dan Self Regulated Learning Terhadap Hasil Belajar Kognitif IPS. Jurnal Penelitian Kependidikan, 23(1): $48-57$.

Perwita, A. A., \& Yani, Y. M. 2005. Pengantar Ilmu Hubungan Internasional, Bandung: PT. Remaja Rosdakarya.

Rahmatullah, M. 2011. Pengaruh pemanfaatan media pembelajaran film animasi terhadap hasil belajar. Jurnal Penelitian Pendidikan, 12(1):178-186.

Sari, A. R. 2013. Strategi Blended Learning Untuk Peningkatan Kemandirian Belajar dan Kemampuan Critical thinking Mahasiswa di Era Digital. Jurnal Pendidikan Akuntansi Indonesia, 11(2).

Sofiana, N. 2015. Implementasi Blended Learning Pada Mata Kuliah Extensive Listening. Tarbawi: Jurnal Pendidikan Islam, 12 (1).

Sriwardiningsih, E. (2014). Faktor-Faktor yang Memengaruhi Perilaku Belajar Mahasiswa E-Learning. Binus Business Review, 5(2): 564-570.

Sulistiyoningsih, T., Kartono, K., \& Mulyono, M. 2015. PBL Bernuansa Adiwiyata Dengan Blended Learning Untuk Meningkatkan Kemampuan Pemecahan Masalah Dan Karakter Peduli Lingkungan. Unnes Journal of Mathematics Education Research, 4(2). 